\title{
Adoption of Good Agronomic Practices (GAP) Among Smallholder Rice Farmers in Nigeria Agricultural Transformation Agenda
}

\author{
Omolehin. R. A. \\ Department of Agricultural Economics and Extension, Federal University, Oye Ekiti, Nigeria \\ Oyewole. S. O. \\ Forestry Research Institute of Nigeria, Ibadan, Nigeria \\ Muhammed Lawal \\ Department of Agricultural Economics, University of Ilorin, Nigeria \\ Coker Alexander Ayodeji \\ Department of Agricultural Economics, Federal University of Technology, Minna, Nigeria
}

\begin{abstract}
This study assessed the adoption rate and identified factors influencing adoption of rice technologies among participants of Agricultural Transformation Agenda across the targeted implementation zones of Adani-Omor, Bida-Badeggi, Kano-Jigawa and Kebbi-Sokoto. Multi-stage sampling procedure was used in selecting eighty respondents for the study. The data were collected with the aid of structured questionnaire. Descriptive statistics and Tobit regression model were employed in the analysis of data. The study revealed that majority of farmers participating in Agricultural Transformation Agenda Project (ATASP-1) are youths and still in their active age as indicated by the average age of 42 years. About $62 \%$ have secondary and tertiary education. On the gender distribution of the people engaged in ATASP-1 project, it was revealed that about $92 \%$ were male while only $8 \%$ were female. Substantial numbers of technologies were disseminated on rice being promoted under ATASP-1 project and the adoption rate of these technologies was very high. More than three-quarter of the respondents have adopted technologies introduced to them. Adoption of rice technologies among participating farmers is largely depends on socioeconomic characteristics of farmers such as age, education and gender of the respondents. The study recommends that there should be continuous training of farmers on the importance of these technologies as well as techniques behind their utilization to ensure continuous usage of the adopted technologies. Women should be encouraged to participate more in the project and to take up farming as a business. Also, adequate attention should be given to farmers socioeconomic characteristics as these are the determinants of technology adoption.
\end{abstract}

Keywords: Adoption, GAP, Rice Farmers, Agricultural Transformation Agenda

DOI: $10.7176 / \mathrm{JESD} / 10-15-02$

Publication date: August $31^{\text {st }} 2019$

\section{Introduction}

Agricultural productivity in many developing countries is constrained by poor farming techniques and practices being used by most smallholder farmers. The poor performance of Nigerian farmers is attributed to their lack and use of good agricultural practices and poor value attached to improved farm practices. In Nigeria, unsustainable agricultural practices have led to poor agricultural productivity, which is a major determinant of food insecurity (Ayuk, 2001). The current agronomic practices by most farmers have no measures of reducing environmental and socioeconomic problems. This will put future food, fodder and fibre production and ecosystem services under additional risk and uncertainty. Poor soil fertility as a result of degradation has put crop production at a risk. Changes in the amount of rain, increased rainfall intensity and changes in rainfall patterns and recurrent droughts and/or floods would lead to decreased resource productivity and production.

Most studies on the adoption of Good Agronomic Practices (GAPs) showed that adoption provides higher yields and income (Manda et al., 2016). Despite the benefits attributed to the adoption of sustainable farm practices, their adoption rates remain low in sub-Saharan Africa (Kassie et al., 2015; Teklewold et al., 2013). Understanding the factors that affect the adoption of GAPs can provide guidance into identifying key drivers and areas that could enhance the use of these practices. However, the majority of earlier studies on the adoption of GAPs have focused on a single technology (Mazvimavi and Twomlow 2009; Arslan et al., 2014).

One of the initiatives of government to boost agricultural production is Agricultural Transformation Agenda (ATA). The overall objective was to increase agricultural production in order to increase domestic food production and generate employment. The Nigeria Agricultural Transformation Agenda (ATA) is an initiative by which the Federal Ministry of Agriculture and Rural Development envisions bringing agriculture back to the center of 
Nigeria's economy that it once occupied, and by so doing solving the problems of rural poverty, youth unemployment and over-reliance on imported foods. Further, it is the mechanism by which Nigeria can replicate the agriculture-driven economic success stories of countries such as Brazil, Thailand, China, Malaysia and Indonesia and, closer to home, Kenya and Malawi. In summary, the ATA is to bring about creation of more than 3.5 million jobs along the value chains of rice, cassava, sorghum, cocoa and cotton; and achieve food security by increasing production of key staple food of rice, cassava, and sorghum by 20 million metric tons (rice, 2 million metric tons; cassava, 17 million metric tons; sorghum, 1 million metric tons).

While the production of staple foods has risen sharply over the last twenty-five years, production cannot yet cover the rising demand for staples, particularly grains. Nigeria alone grows about $50 \%$ of the total production in West Africa. As is the case in nearly all West African countries, rise in grain production is due largely to the expansion of cultivated land than to any significant improvement in yields. Meanwhile rice yield has stagnated at about $2 \mathrm{t}$ /ha on the average since 1990 (Inter reseaux, 2015). Low agricultural productivity in Nigeria has been largely due to low inappropriate and inadequate application of good agronomic practices such as fertilizer, improved seed utilization, and a wide gamut of on-farm and post-farm activities related to food safety, food quality and food security, the environmental impacts of agriculture (FMARD, 2011). In order to take corrective measures and achieve the ATAPS-1 targets for staple crops, concerted efforts must be made to provide information on the adoption of GAPs among the farmers

Regardless of this intervention and other initiatives by government to support rural livelihood and also boost agricultural productivity, over- exploitation and poor management practices will lead to reduced fertility and availability of natural resources (Global Environment Facility, (GEF), 2010). Therefore, good agronomic and management practices remain a practical pathway for farmers to enhance the productivity and resilience of agricultural production systems while conserving the natural resource base (Teklewold et al., 2013; Kassie et al., 2013).

The importance of the key staple food crops especially rice for which ATASP-1 is to bring about increase in production cannot be over emphasized. Rice is the staple food in many countries of the world. Over the years, the crop's demand has risen steadily and its growing importance is evident, given its important place in the strategic food security planning policies of many countries (Saka et al., 2005). In Nigeria, the rising import bills on rice coupled with the increasing demand for the commodity has led successive Nigerian governments to step up policies aimed at remedying the country's supply deficit for the commodity. Despite various interventions to boost rice production, Nigeria still depend on the importation of rice. This could be attributed to poor production technologies characterized by low productivity.

This study is therefore essential because of the need to increase agricultural productivity especially rice farming through the use of improved agricultural technologies and practices by the smallholder farmers in the face of acute food shortage and worsened living conditions. In order to take corrective measures and achieve the ATAPS-1 targets for food crop production, concerted efforts must be made to provide information on the adoption of GAP among the farmers. This will provide a farm-level feedback for appropriate policy targeting at improving status of crop production. The study therefore examined the rate of adoption of agronomic practices among farmers and the underlining factors that influence farmers' adoption decisions.

\section{Methodology}

The study was conducted in the four staple crop processing zones SCPZs across the country. These zones are: Adani-Omor covering Anambra and Enugu States in the south east, Bida-Badeggi SCPZ in Niger State in the north central, Kano-Jigawa SCPZ and Kebbi-Sokoto SCPZ these two zones are located in the north western part of the country. There is variation in climatic conditions across the zones with Adani-Omor located in the tropical rainforest in the South East, Bida-Badeggi located in the Guinea Savanna while Kano-Jigawa and Sokoto-Kebbi are located in the Sudan Savanna ecological zone of the country. The study focused solely on the program beneficiaries in ascertaining the rates of adoption of technologies disseminated on rice production by ATASP-1

\subsection{Sampling Procedure and Sample Selection}

Multi-stage sampling procedure was used in selecting respondents for the study. However, given the preponderance of production-based value chain actors, 80 samples comprising 20 respondents were randomly selected from each of SCPZ zone. These zones were Kebbi-Sokoto, Kano-Jigawa, Bida-Badeggi and Adani-Omor SCPZ. The sampling was done to cover all the 33 local government areas (LGAs) where the program is being executed across the country.

\subsection{Methods of Data Collection}

Data collection was through primary data. These were solicited through the use of structured questionnaire. The questionnaires were administered to participating farmers under the programme. Data collected covered background information, institutional information, technologies disseminated, mode of practicing technology, 
rates of adoption and constraints to adoption of GAPs.

\subsection{Method of Data Analysis}

The study employed descriptive statistics and Tobit regression model in the analysis of data collected for this study. Descriptive statistics such as mean, frequency, standard deviation and count were used. Tobit model was used to ascertain the factors influencing the adoption of good agronomic practices among ATASP-1 farmers. The model is specified as follows in the implicit form:

$$
\boldsymbol{Y} o^{*}=\boldsymbol{X} \boldsymbol{\beta}+\mu o
$$

Where $Y_{O}$ is the latent (hidden) dependent variable for the $\mathrm{O}^{\text {th }}$ farm; $X_{\mathrm{o}}$ is the vector of independent variables, vector $\boldsymbol{\beta}$ comprises the unknown parameters to be estimated that are associated with the independent variables for the $\mathrm{O}^{\text {th }}$ farm, and $\mu o$ is an independently distributed error term assumed to be normally distributed with zero mean and constant variance. The independent variables considered were gender, age, marital status, education, household size and farm size. Other variables in the model were farmers' experience, extension visits, credit and association.

\section{Results and Discussion}

\subsection{Socio-economic characteristics of the respondents}

The socioeconomic variables of the farmers are very important for good planning and decision making by policy makers. The composition of these variables can also make or mar the ability of farmers' effectiveness in production process. The age structures of rice farmers under ATASP-1 as presented in Table 1 showed that about $14 \%$ of the farmers are within 21-30 years of age. Those within 31-40 years constitute 21\%. The average age was 43 years. The implication is that the project has encouraged youth participation in food production as a business and this has a lot of significant for future food production and food security for the country. On the gender distribution of the people engaged in ATASP-1 project, it was revealed that about $92 \%$ were male while only $8 \%$ were female. This could be due to the fact that women are mostly found in processing and value addition activities.

As shown in Table 1, majority (97.5\%) of the respondents were married. The significance of marital status among rural communities with respect to farm business and livelihood activities can be explained in terms of the supply of agricultural family labour. It is expected that family labour would be more available where the household heads are married. It is very significant that participating farmers had one form of education or the other and surprisingly, of the total participants, about $62 \%$ have secondary and tertiary education. The implication of this is that these participants are better positioned to understand and adopt innovations that will facilitate productivity and better livelihood as opposed to when we have illiterate participants. About $20 \%$ of the household members have family size of between 1-5 persons per household. The average family size was 11 people per household. The implication of fairly large family size is that in some cases where the members are over 18 years old, they could give helping hands in farming particularly during planting, weeding and harvesting of crops. The study also found that total land areas between $0.1-0.5$ available for $6 \%$ of the respondents, those with land area of $0.51-1.0$ represents about $38 \%$ of the participants, those with total land area of 1.1-1.5 represents $10 \%$, while those with over 2 ha of total land area represents $35 \%$. The mean land area for the respondents was 2.1 ha. From this finding it is very clear that farmers participating in the project are mostly small scale farmers. The average year of experience in rice cultivation was 18 years. About $98 \%$ of rice farmers claimed they have contact with extension agents while about $2 \%$ claimed they do not. 
Table 1: Structure of farmer's household across crops in the ATASP-1 Project

\begin{tabular}{|c|c|c|}
\hline Socio-economic characteristic & Frequency & Percentage \\
\hline \multicolumn{3}{|l|}{ Age } \\
\hline $21-30$ & 13 & 16.25 \\
\hline $31-40$ & 17 & 21.25 \\
\hline $41-50$ & 30 & 37.5 \\
\hline $51-60$ & 18 & 22.5 \\
\hline$>60$ & 2 & 6.67 \\
\hline Mean & 43.6 & 43.6 \\
\hline \multicolumn{3}{|l|}{ Gender } \\
\hline Male & 74 & 92.5 \\
\hline Female & 6 & 7.5 \\
\hline \multicolumn{3}{|l|}{ Marital Status } \\
\hline Married & 78 & 97.5 \\
\hline Single & 2 & 2.5 \\
\hline \multicolumn{3}{|l|}{ Others } \\
\hline \multicolumn{3}{|l|}{ Education } \\
\hline None & 2 & 2.5 \\
\hline Koranic & 10 & 12.5 \\
\hline Primary & 12 & 15.0 \\
\hline Juninor & 4 & 5.0 \\
\hline Senior secondary & 17 & 21.3 \\
\hline Tertiary & 33 & 41.3 \\
\hline Adult education & 2 & 2.5 \\
\hline \multicolumn{3}{|l|}{ Household size } \\
\hline $1-5$ & 16 & 20.0 \\
\hline $6-10$ & 25 & 31.3 \\
\hline $11-15$ & 24 & 30.0 \\
\hline$>15$ & 15 & 18.8 \\
\hline Mean & 11 & 11 \\
\hline \multicolumn{3}{|l|}{ Farm size } \\
\hline $0.1-0.5$ & 5 & 6.25 \\
\hline $0.51-1.0$ & 30 & 37.5 \\
\hline $1.1-1.5$ & 8 & 10 \\
\hline $1.51-2.0$ & 9 & 11.3 \\
\hline$>2.0$ & 28 & 35.0 \\
\hline Average & 2.1 & 2.1 \\
\hline \multicolumn{3}{|l|}{ Farming Experience } \\
\hline $1-10$ & 23 & 28.75 \\
\hline $11-20$ & 36 & 45.0 \\
\hline $21-30$ & 12 & 15.0 \\
\hline$>30$ & 9 & 11.25 \\
\hline Average & 17.9 & 17.9 \\
\hline \multicolumn{3}{|l|}{ Extension visit } \\
\hline Yes & 78 & 97.5 \\
\hline No & 2 & 2.25 \\
\hline
\end{tabular}

3.2 Technologies disseminated on rice production

There were many technologies disseminated to rice farmers under the project as shown in Table 2. It was revealed that all the farmers were aware of improved rice varieties while site selection for production was known to about $89 \%$ of the farmers under the project and all the farmers- $100 \%$ were aware of field preparation method for rice production. More so, about $99 \%$ were aware of the right planting season for rice production while about $98 \%$ were aware of crop establishment. Other technologies these farmers are familiar with are weed management and fertilizer application method of by all the participating farmers and finally, pest control were known to about $99 \%$ of the participating farmers. It is hoped that these level of awareness will stimulate improved adoption by these farmers and consequently improved level of productivity. 
Table 2: Technologies disseminated on rice

\begin{tabular}{lll}
\hline Technologies & Frequency & Percentage \\
\hline Improved varieties (Faro 44, Faro 52, Faro 60 and Faro 61 & & \\
Yes & 80 & 100 \\
No & - & - \\
Site/Land preparation & 71 & 88.8 \\
Yes & 5 & 6.3 \\
No & 80 & 100 \\
Field preparation & 77 & 96.2 \\
Seed preparation & 3 & 3.8 \\
Yes & - & - \\
No & & \\
Determine planting season & 79 & 98.8 \\
Yes & 1 & 1.2 \\
No & & \\
Crop establishment & 78 & 97.5 \\
Yes & 2 & 2.5 \\
No & & \\
Weed management & 80 & 100 \\
Yes & - & - \\
No & & \\
Fertilizer application & 80 & 100 \\
Yes & - & - \\
No & & \\
Pest and Disease control & 79 & 98.8 \\
Yes & 1 & 1.2 \\
No & &
\end{tabular}

3.3 Rate of adoption of technologies disseminated to rice farmers

As observed from Table 3, there was an impressive level of technology adoption under ATASP-1 project. It was found that improved seed and weed management recorded 100\% adoption levels while field preparation, determination of appropriate planting period and crop establishment all recorded about $99 \%$ levels of adoption while site preparation and fertilizer application recorded about $98 \%$ levels of adoption and the least which was pest and diseases control was 95\% level of adoption. This is an indication of the high interest these farmers have dedicated in joining the train of rice production. This adoption rate has raised the hope that we are on course towards becoming a major rice producing nation and able to produce enough to meet national demands thus conserving our scarce foreign reserve for better use.

Table 3: Rate of adoption of rice technologies

\begin{tabular}{llll}
\hline S/No & Technologies & Frequency* & Percentage \\
\hline 1 & Improved varieties (Faro 44, Faro 52, Faro 60 and Faro 61 & 80 & 100 \\
2 & Site/Land preparation & 78 & 97.5 \\
3 & Field preparation & 79 & 98.8 \\
4 & Seed preparation & 77 & 96.3 \\
5 & Determine planting season & 79 & 98.8 \\
6 & Crop establishment & 79 & 98.8 \\
7 & Weed management & 80 & 100 \\
8 & Fertilizer application & 78 & 97.5 \\
9 & Pest and Disease control & 76 & 95.0 \\
\hline
\end{tabular}

\subsection{Factors Influencing Adoption of rice Technologies}

As shown in Table 4, gender and educational level of the respondents were significantly influencing all the technologies introduced to the farmers. The estimated parameters obtained for these variables were positive and significant at $1 \%$ level of probability. Educated farmers tend to know and understand the importance of using improved technologies for increased output in rice production so the more educated a farmer is the more he will be willing to use improved farming techniques. Age of the farmers was found to be positively related to adoption of site/land preparation, field preparation, seed preparation, determining planting season, crop establishment and weed management. The significant and positive coefficients obtained for age is an indication that older farmers tends to adopt rice technologies compared to young farmers. This could be attributed to the accumulation of experience in rice production. Marital status was equally found significant among the variables influencing 
adoption of rice technologies asides crop establishment and weed management. The estimated parameters for marital status were positive. The implication of this is that married farmers tend to adopt adoption of rice technologies compared to those that are still single. This could be due to the fact that married individual are known to be very responsible willing to get maximum returns from whatever investment they engaged in. Farming experience is another variable that significantly influence rice technology adoption. The more experience a farmer is the more his understanding of rice technology will be and ability to boost crop production through adoption of improved technologies. Other important factor is credit. Access to credit was found influencing adoption of some technologies introduced to the farmers. Credit could facilitate adoption of technologies as credit is needed to buy necessary input like fertilizer, so the more access to credit a farmer has the more inputs he will use. Finally, membership of association was significantly related to adoption of fertilizer application in rice production. Membership of association is known to facilitate farmers' access to inputs like seeds, fertilizers and agrochemicals. So being a member of association will facilitate adoption of recommended fertilizer in rice production.

\section{Conclusion and Recommendations}

The study revealed that majority of ATASP-1 participating farmers are youths and still in their active productive age. This has a lot of significant for future food production and food security for the country. Substantial numbers of technologies were disseminated on rice being promoted under ATASP-1 project and the adoption rate of these technologies was very high. Adoption of rice technologies among participating farmers is largely depends on socioeconomic characteristics of farmers such as age, education and gender of the respondents. The study recommends that there is need for continues training of farmers on the importance of these technologies as well as techniques behind their utilization to help these farmer continue to adopt them. Women should be encouraged to participate more in the project and to take up farming as a business.

\section{References}

Arslan, A., McCarthy, N., Lipper, L., Asfaw, S and Cattaneo, A. (2014). Adoption and intensity of adoption of conservation farming practices in Zambia', Agriculture, Ecosystems \& Environment, 187: 72-86.

Ayuk, E.T. (2001). Social, economic and policy dimensions of soil organic matter management in sub-Saharan Aftica: Challenges and opportunities. Nutrient cycling in agro-ecosystem. 61: 183-195 (www.springerlink.com/ content/gt87- 225276n/138) viewed on 10th November 2007.

Federal Ministry of Agriculture \& Rural Development, (2011). Agricultural Transformation Agenda: We Will Grow Nigeria's Agriculture Sector.

GEF. (2010). Scaling up Sustainable Land Management Practice and Coordination. Project Information. GEFSEC PROJECTID: 3384.

Inter reseaux (2015). Staple Crop Production and Consumption: Nigeria on the Way to Food Self-sufficiency. Retrieved on 4/11/17 from http://www.inter-reseaux.org/publications/revue-grain-de-sel/51-special-issuenigeria/article/staple-crop-production-and

Kassie, M., Teklewold, H., Jaleta, M., Marenya., P and Erenstein, O. (2015). 'Understanding the adoption of a portfolio of sustainable intensification practices in eastern and southern Africa', Land Use Policy. 42: 400411.

Mazvimavi, K and Twomlow, S. (2009). 'Socioeconomic and institutional factors influencing adoption of conservation farming by vulnerable households in Zimbabwe', Agricultural Systems, 101 (1-2): 20-29

Manda, J, Alene, AD, Gardebroek, C, Kassie, M \& Tembo, G 2016, 'Adoption and Impacts of Sustainable Agricultural Practices on Maize Yields and Incomes. Evidence from Rural Zambia', Journal of Agricultural Economics, 67(1):130-153.

Saka, J.O, Okoruwa, V.O, Lawal, B.O and Ajijola, S. 2005. Adoption of Improved rice varieties among small holder farmers in South-Western Nigeria. World Journal of Agricultural Science (1): 42-49.

Teklewold, H, Kassie, M, Shiferaw, B \& Köhlin, G 2013, 'Cropping system diversification, conservation tillage and modern seed adoption in Ethiopia: Impacts on household income, agrochemical use and demand for labor', Ecological Economics, 93: 85-93.

Wilken, G.C. (1991). Sustainable agriculture is the solution but what is the problem? Occasional Paper No 14, United States Agency for International Development, Washington DC. Pp. 1-19 
Table 4: Analyses of factors influencing adoption of disseminated technologies to rice farmers

\begin{tabular}{|c|c|c|c|c|c|c|c|c|c|}
\hline \multicolumn{10}{|c|}{ Factors influencing adoption of rice technologies } \\
\hline Variables & A & B & C & D & $\mathbf{E}$ & $\mathbf{F}$ & G & H & I \\
\hline Gender & $0.302\left(5.47^{* * *}\right)$ & $0.302\left(5.75^{* \star \star}\right)$ & $0.301\left(5.75^{* \star *}\right)$ & $0.282\left(4.99^{* * *}\right)$ & $0.297\left(4.74^{* * *}\right)$ & $0.286\left(4.11^{* * *}\right)$ & $0.274(3.99)$ & $0.288\left(4.74^{* * *}\right)$ & $0.322\left(4.56^{* * *}\right)$ \\
\hline Age & $0.003(1.7)$ & $0.005\left(2.88^{\star * \star}\right)$ & $0.003\left(2.88^{* \star *}\right)$ & $0.004\left(2.13^{* *}\right)$ & $0.006\left(2.78^{\star \star \star}\right)$ & $0.001(0.56)$ & $0.009\left(3.85^{* * \star}\right)$ & $0.003(1.44)$ & $0.003(1.56)$ \\
\hline Marital status & $0.138\left(3.68^{* \star *}\right)$ & $0.135\left(3.78^{\star \star \star}\right)$ & $0.138\left(3.78^{* \star *}\right)$ & $0.131\left(3.42^{\star \star \star \star}\right)$ & $-0.018(-0.37)$ & $0.147\left(3.11^{* \star \star}\right)$ & $-0.061(-1.05)$ & $0.116\left(2.81^{\star \star \star}\right)$ & $0.148\left(3.09^{* \star \star}\right)$ \\
\hline Education & $0.039\left(3.59^{* \star *}\right)$ & $0.030\left(2.91^{* * *}\right)$ & $0.039\left(2.91^{* * *}\right)$ & $0.039\left(3.45^{* * *}\right)$ & $0.048\left(3.87^{* * *}\right)$ & $0.046\left(3.34^{* * *}\right)$ & $0.045\left(3.3^{* \star * *}\right)$ & $0.052\left(4.33^{* * *}\right)$ & $0.038\left(2.76^{* * *}\right)$ \\
\hline Household size & $0.004(1.06)$ & $0.002(0.44)$ & $0.004(0.44)$ & $0.0001(0.03)$ & $0.008(1.75)$ & $0.006(1.16)$ & $0.0001(0.01)$ & $-0.003(-0.7)$ & $-0.007(-0.14)$ \\
\hline Farm size & $0.004(0.43)$ & $0.015(1.5)$ & $0.004(1.50)$ & $0.013(1.24)$ & $0.003(0.26)$ & $0.008(0.63)$ & $0.004(0.32)$ & $0.016(1.36)$ & $0.023\left(1.75^{*}\right)$ \\
\hline Farming experience & $0.003(1.21)$ & $0.002(1.02)$ & $0.002(1.02)$ & $0.003(1.44)$ & $0.004(1.81)$ & $0.002(0.59)$ & $0.003(1.06)$ & $0.004\left(1.79^{\star}\right)$ & $0.004(0.16)$ \\
\hline Extension contact & $0.001(0.44)$ & $0.001(0.64)$ & $0.001(0.64)$ & $0.0001(0.06)$ & $0.004\left(2.42^{\star \star}\right)$ & $0.001(0.31)$ & $0.003\left(1.72^{\star}\right)$ & $0.0001(0.22)$ & $0.004(0.17)$ \\
\hline Access to credit & $0.007(1.62)$ & $0.005(1.19)$ & $0.007(1.19)$ & $0.008(1.7)$ & $0.004(0.87)$ & $0.005(0.87)$ & $0.003(0.55)$ & $0.008\left(1.67^{\star}\right)$ & $0.005(0.09)$ \\
\hline Association & $0.012(0.76)$ & $0.014(0.92)$ & $0.012(0.92)$ & $0.018(1.06)$ & $0.010(0.54)$ & $0.026(1.27)$ & $0.028(1.41)$ & $0.031\left(1.74^{*}\right)$ & $0.023(1.13)$ \\
\hline
\end{tabular}
$* * *, * *, *=$ Significant at 1,5 and 10 percent

$\mathrm{A}=$ Improved varieties (Faro 44, Faro 52, Faro 60 and Faro 61, $\quad \mathrm{B}=$ Site/land $\quad$ preparation, $\quad \mathrm{C}=$ Field preparation $\quad \mathrm{D}=$ Seed preparation, $\quad \mathrm{E}=$ determining planting season, $\quad \mathrm{F}=$ crop establishment $\mathrm{G}=$ weed management $\mathrm{H}=$ fertilizer application, $\quad \mathrm{I}=$ pests and disease control 